\title{
Ensino de literaturas e decolonialidade: por uma educação literária democrática
}

\author{
Rodrigo Corrêa Martins Machado ${ }^{\mathrm{a}}$ (D) \\ Douglas Vinicius Souza Silva ${ }^{\mathbf{b}}$ (D)
}

\begin{abstract}
RESUMO
O que se entende por "democracia" e por "direitos humanos" quando se defende uma educação literária democrática? E quando se defende a democratização das artes, em especial, da literatura? Partindo de um incômodo com algumas respostas a essas questões, cristalizadas na crítica literária e nas práticas de ensino de literaturas, este artigo tem o objetivo de problematizar e refletir sobre as concepções de democracia e de direitos humanos que embasam o ensino de literaturas no Brasil, propondo uma guinada a partir das teorias decoloniais. Para isso, revisitamos a obra "O direito à literatura", de 1988, de Antonio Candido (2011), que se tornou referência básica em crítica, teoria, didática ensino de literaturas atéos dias de hoje, demonstrando como sua teoria se concentra na classe econômica e na apresentação dos bens culturais nacionais-universais em via de mão única para os estudantes desprivilegiados. Posteriormente, ainda que reconheçamos a relevância histórica
\end{abstract}

\footnotetext{
aUniversidade Federal de Ouro Preto (UFOP). Ouro Preto, Minas Gerais, Brasil.

E-mail: rodrigo.machado@ufop.edu.br

bUniversidade Estadual de Campinas (UNICAMP). Campinas, São Paulo, Brasil.

E-mail: dodo.vinicius.ds@gmail.com
}

\section{Como citar:}

MACHADO, R.C.M.; SILVA, D.V.S. Ensino de literaturas e decolonialidade: por uma educação literária democrática. Gragoatá, Niterói, v.26, n.56, p. 1207-1240, 2021. <https://doi.org/10.22409/ 
da teoria de Candido, buscamos demonstrar, a partir da leitura de hooks (2017; 2019), Walsh (2009), Melo (2020) e outros autores, sua insuficiência para lidar com a realidade contemporânea dos jovens dentro e fora da escola. A partir dai, refletimos sobre a necessidade de um ensino de literaturas democrático, em direitos humanos, que se construa em diálogo e negociação não apenas com os grupos subalternos pertencentes a classes econômicas inferiores, mas também com os grupos subalternizados pela etnia, raça, gênero, sexualidade, localização geográfica etc., isto é, um ensino que se construa inclusive através da escuta.

Palavras-chave: Educação literária. Direitos humanos. Democracia. Decolonialidade. Ensino de Literatura.

\section{Introdução}

Nosso trabalho tem o objetivo de levantar discussões e trazer reflexões a respeito das concepções de democracia e de direitos humanos em relação ao campo do ensino de literaturas, sobretudo, no que tange às ideias difundidas e cristalizadas nesse campo do pensamento, aqui exemplificadas pela teoria de Antonio Candido em "O direito à literatura" (2011). A nosso ver, essas ideias precisam ser revisitadas a fim de que a educação literária se torne cada vez mais democrática, tanto em relação às escolhas de obras a serem trabalhadas na escola, quanto a tema e autores. Ao pensarmos em um ensino democrático em direitos humanos, imaginamos que é um ensino feito com, por e para o povo, composto por uma rica multiculturalidade, múltiplas formas de viver gêneros e sexualidades, posições político-econômicas, etnias etc. $\mathrm{Ou}$ seja, no caso do ensino de literaturas, que não seja um espaço hierarquizador e reprodutor de uma ideologia excludente, racista, eugenista e sectarista. Devemos considerar com bell hooks (2017, p. 51), que "[...] a maioria de nós frequentamos escolas onde o estilo de ensino refletia a noção de uma única norma de pensamento e experiência, a qual fomos encorajados a crer que fosse universal". Isso também acontece no Brasil, onde as escolas ensinam conteúdos centrados nas culturas europeias como universal e descarta os saberes indígenas, 
de origem africana e das mais diversas culturas subalternas. Nesse sentido, vemos que:

a cultura do povo a ser "modernizado" precisa ser descartada para algum tipo de projeto nacional-ocidental se viabilizar. Para a nação formar-se, dentro dos parâmetros nacionaisocidentais, ela precisa seguir alguns caminhos, ao mesmo tempo que necessita rechaçar claramente outros trajetos. (MELO, 2020, p. 36)

Logo, pensamos na construção de um ensino democrático que promova os direitos humanos e que inclua as mais variadas representações de mundo, culturas e vivências. Para isso, consideramos que novos e maiores esforços têm de ser feitos (na práxis e na teoria) a fim de questionar o ensino instituído, propondo modos de ação e reflexão que contemplem os sujeitos historicamente subalternizados. A reflexão a respeito de democracia, direitos humanos e ensino que desenvolvemos em nosso texto, surgiu inicialmente a partir das leituras sobre decolonialidade que viemos fazendo, uma vez que elas nos permitem questionar algumas postulações cristalizadas em nossa sociedade e no cerne do ensino de literaturas, como é o caso da ideia de democracia que é divulgada por muitos professores quando justificam a importância de se trabalhar exclusivamente os cânones literários com os alunos pertencentes a grupos historicamente subalternizados.

Grande parte dos docentes, respaldados pelo discurso da crítica literária, afirma que é imprescindível que os alunos marginalizados se apropriem do conhecimento da "alta literatura", dos "grandes escritores" de modo a que possam acessar as maiores esferas de poder e usufruir da "verdadeira arte". Por trás desse discurso, há sempre a premissa recôndita que a esses alunos deve ser levada a "verdadeira cultura", a "verdadeira literatura", a "verdadeira música", a "verdadeira arte", como se, por pertencerem a classes-espaços-sexualidades que não são os das esferas de poder, não tivessem também arte, literatura e cultura.

Diante disso, os estudos da decolonialidade contribuem enquanto potência/postura ética e política para se refletir e modificar estruturas fixas no que diz respeito ao ensino de literaturas, uma vez que tais teorias foram elaboradas sobretudo por pensadores latino-americanos (mas também por 
${ }^{1 \mathrm{~T}}$ radução nossa.

"A decolonialidade é, então, a energia que não se deixa manejar pela lógica da colonialidade nem crê em contos de fadas da retórica da modernidade. Se a decolonialidade tem uma variada gama de manifestações - algumas não desejáveis, com as que hoje Washington descreve como 'terroristas' - 0 pensamento decolonial é, então, o pensamento que se desprende e se abre [...] encoberto pela racionalidade moderna, montado e fechado nas categorias do grego e do latim e das seis línguas imperiais modernas". pensadores de outros países do cone sul) que se concentram em analisar crítica e profundamente como a colonialidade se impôs nas estruturas de poder na América Latina, nos modos de saber, ser e pensar dos povos dos países latino-americanos, desvendando a produção de conhecimento de uma episteme principalmente eurocêntrica e da América do Norte.

Segundo nos diz Walter Mignolo (2007), o pensamento decolonial emergiu da própria fundação da ideia de colonialidade/modernidade, como contrapartida a esta ideia. Nas Américas, esse pensamento teria ocorrido a partir dos indígenas e afro-americanos, encontrando ecos na África e Ásia. O estudioso argentino ainda nos revela que

La decolonialidad es, entonces, la energia que no se deja manejar por la lógica de la colonialidad, ni se cree los cuentos de hadas de la retórica de la modernidad. Si la decolonialidad tiene una variada gama de manifestaciones - algunas no deseables, como las que hoy Washington describe como "terroristas" -, el pensamiento decolonial es, entonces, el pensamiento que se desprende y se abre (...), encobierto por la racionalidad moderna, montado y encerrado en las categorias del griego y del latín y de las seis lenguas imperiales modernas (MIGNOLO, 2007, p. 27) ${ }^{1}$.

A abertura assinalada por Mignolo é profícua quando a entendemos como uma nova possibilidade de construção e resgate de saberes produzidos por povos subalternizados, os quais agora buscam se colocar como protagonistas de suas próprias histórias, fugindo dos pensamentos duais impostos pelo eurocentrismo (bem/mal; homem/mulher; ocidente/ oriente), e acolhendo (visibilizando) muitos outros sujeitos que foram massacrados, física e culturalmente, ao longo dos anos. Logo, os pressupostos da decolonialidade investigam esse sistema eurocêntrico e excludente com o qual buscamos romper, dando-nos uma ampla perspectiva a respeito das hierarquizações historicamente constituídas.

Por fim, nosso artigo se divide em duas partes. $\mathrm{Na}$ primeira delas, estabelecemos um diálogo-crítico com o pensador brasileiro Antonio Candido, dada a importância do pensamento dele para a literatura e, também, para a educação literária brasileira, sobretudo com as noções de democracia e direitos humanos presentes no clássico ensaio "O direito à literatura", de 1988. Essa obra é uma das mais citadas em 
${ }^{2 \mathrm{C}}$ omo defende Alfredo Melo (2020, p. 37) sobre intelectuais e intérpretes do Brasil que reproduziam a lógica colonial apesar do ímpeto de libertar o Brasil das mazelas sociais causadas pela colonização: "não podemos exigir outro posicionamento de autores cujo horizonte intransponível era o nacional-ocidentalismo e suas possibilidades". artigos, dissertações e teses sobre ensino de literatura, em livros didáticos e em produções acadêmicas e pedagógicas das mais variadas ainda hoje, caracterizando tal trabalho como um dos pilares teóricos do ensino de literaturas nas últimas décadas e uma obra incontornável para pesquisas que envolvam sua temática. Ao estabelecermos esse diálogo, longe de questionar a relevância do autor, do texto e das pesquisas desenvolvidas a partir dele ou de cometer o anacronismo de avaliá-lo por meio dos paradigmas contemporâneos ${ }^{2}$, desejamos incluir debates atuais pertinentes à educação literária brasileira.

Na segunda parte do trabalho, buscamos discutir como a concepção centrada apenas na classe tem sido insuficiente para que a escola (e a educação literária) seja democrática não apenas no que diz respeito ao seu acesso, mas ao acolhimento de diferentes grupos sociais subalternizados por motivos que vão além do econômico. Demonstramos como o ambiente escolar ainda pode ser muito excludente e pouco democrático em relação às populações negras, LGBTQI+, mulheres, indígenas e demais grupos subalternizados, que não se sentem representados na instituição escolar e, consequentemente, não se enxergam nela. Desse modo, ao longo de todo o artigo, propomos que pensemos a escola e a educação literária em conjunto com esses grupos subalternizados, de modo que eles sejam sujeitos ativos para a construção de um ensino cada vez mais democrático.

\section{Democratização pela "classe" e cultura em via de mão única em Candido}

Em relação ao pensamento da crítica literária canônica brasileira, refletimos que é imprescindível verificar qual discurso vem sendo difundido, sobretudo em relação ao ensino. Nesse sentido, acreditamos que pela importância e grande difusão, devemos abordar o famoso ensaio de Antonio Candido intitulado "O direito à literatura", de 1988 (2011). No texto, o autor contextualiza sua concepção de democracia denunciando a desigualdade econômica latente, já que, "em certos países, como o Brasil, quanto mais cresce a riqueza, mais aumenta a péssima distribuição dos bens", enquanto deveria haver uma "distribuição equitativa dos bens materiais" e imateriais em um estado democrático de fato (CANDIDO, 2011, p. 171). Ao longo 
${ }^{3}$ Conforme Marcos Natali (2006, p. 34), "segundo estudos antropológicos, alguns dos quais citados pelo próprio Antonio Candido, não está de forma alguma claro que a primeira afirmação universalista - todos têm literatura - seja de fato verdadeira". do ensaio, Candido se propõe a pensar a literatura enquanto um direito inalienável do ser humano, já que "pensar em direitos humanos tem um pressuposto: reconhecer que aquilo que consideramos indispensável para nós é também indispensável para o próximo", vinculando, portanto, os direitos humanos à democracia, que têm em comum o combate à desigualdade e a distribuição equitativa do indispensável. Seu posicionamento é de fundamental importância num momento em que, como postula: "a tendência mais funda é achar que nossos direitos são mais urgentes que os do próximo" (CANDIDO, 2011, p. 174).

Quanto à literatura, inicialmente, Candido (2011) aponta que não há povos e seres humanos que vivam sem o literário, sem o que ele chama de "alguma espécie de fabulação", sendo por isso algo universal e comum à humanidade, um direito por corresponder a necessidades básicas ${ }^{3}$. $\mathrm{O}$ autor justifica que os textos literários têm sido poderosos instrumentos de instrução e educação presente nos currículos, uma vez que as criações ficcionais, dramáticas e poéticas acabam por refletir os impulsos, crenças, sentimentos e normas da sociedade.

A partir daí, Candido (2011, p. 174) parte para a análise da democratização e dos direitos humanos do ponto de vista das artes, e constata que as pessoas "afirmam que o próximo tem direito, sem dúvida, a certos bens fundamentais, como casa, comida, instrução, saúde, [...] mas será que pensam que o seu semelhante pobre teria direito a ler Dostoiévski ou ouvir os quartetos de Beethoven?". Concordamos que todos têm o direito de ler e ouvir clássicos, que a escola é o lugar de apresentar essas produções desconhecidas pelas classes desprivilegiadas, e, por isso, a abordagem do direito às classes subalternizadas é, de fato, essencial. Porém, ainda sem incluir o olhar interseccional crítico em nossa análise, questionamos: não teriam os pobres também o direito a ter suas literaturas e músicas (e produções culturais de um modo geral) igualmente ouvidas, divulgadas e legitimadas? Não teriam direito a aprender a relacionar, sempre no viés dialógico e de negociação de sentido, as várias culturas presentes no país (ou fora dele)? Não teria a escola o papel de, senão garantir, ao menos estimular esses dois pontos?

Candido não nega esses direitos e poderia não ser o seu foco trabalhar com esse olhar naquele momento, mas essas problematizações se fazem importantes ao observarmos no 
${ }^{4}$ A importância do termo "arco" se dá pela heterogeneidade dos atores desse jogo dialético, que vão desde conservadores retrógrados até progressistas preocupados com os direitos dos subalternos (como Antonio Candido)

Por isso, arco "pressupõe uma disposição espacial para gradações e combinações várias entre as múltiplas equivalências construídas para os termos da disputa" (MELO, 2020, p. 29), já que "nacional" e "ocidental" são termos amplos que permitem inúmeras interpretações, das mais inclusivas às mais excludentes, de projeto de país. ensino de literatura vigente, cujas raízes se fincam em Candido, que esses questionamentos ainda não foram totalmente incorporados, resultando na permanência de uma linha abissal (SANTOS, 2007) que separa a cultura de origem dos grupos - não apenas economicamente - marginalizados, à escolar cultura dos privilegiados. Nessa separação abissal, as culturas populares não ocidentais, em todas as manifestações artísticas às margens, são encaradas pela instituição escolar como "um conjunto de obstáculos gerado pela presença não ocidental [que] precisaria ser removido, suavizado, diluído ou domesticado para a nação se modernizar" (MELO, 2020, p. 24). O ensino dos clássicos, para Candido, esbarra nisso: aceita-se a presença do "não ocidental" - apresentado como folclore - difundido espontaneamente na cultura brasileira, mas, no momento de definir os conteúdos escolares, moldados a partir dos estruturados e legitimados saberes ocidentais, que devem ser transmitidos a todos os brasileiros, há espaço apenas para as produções nacionais que se assemelham aos padrões europeus. Configura-se aí a ideia de "arco nacional-ocidental": um "jogo dialético que envolve pertencimento ao Ocidente e certa diferenciação formuladora da singularidade nacional, mas que não rejeitaria o vínculo espiritual com o Ocidente" (MELO, 2020, p. 25) ${ }^{4}$.

Em continuidade, na fronteira tênue entre o que Candido chama de bens incompressíveis - que jamais podem ser suprimidos, como alimento e água - e bens compressíveis como enfeites e cosméticos -, para o autor, está a literatura. Em suas palavras, "o fato é que cada época e cada cultura fixam os critérios de incompressibilidade, que estão ligados à divisão da sociedade em classes, pois inclusive a educação pode ser instrumento para convencer as pessoas de que o que é indispensável para uma camada social não o é para outra" (CANDIDO, 2011, p. 175). O trecho exemplifica, novamente, o foco dado para a divisão de classes, e reconhece a multiculturalidade no estabelecimento dos critérios, mas homogeneíza o problema em si e sua solução por desconsiderar que nessa mesma fronteira tênue em que se encontra a literatura, há também o acolhimento às identidades, o reconhecimento de si e a valorização da própria cultura pela instituição escolar, importantes porque garantem a "integridade espiritual" tal como Candido (2011, p. 176) afirma que a literatura o faz. 
Sem completar essa lacuna, a educação literária, por décadas, tem servido para reforçar que o acesso a produtos culturais eruditos é indispensável para as classes subalternizadas, mas, ao parar a reflexão nesse ponto, acaba por sugerir que o direito de se reconhecer e de se sentir representado pela instituição escolar é apenas das elites dominadoras, já que os grupos subalternizados não têm seus produtos culturais ali legitimados. A escola e a literatura, enquanto instituições, a partir do momento em que pouco reconhecem (quando o fazem) as produções literárias e culturais de sujeitos subalternizados, tornam-se estruturas de opressão que não permitem que as vozes de tais sujeitos sejam escutadas (KILOMBA, 2019, p. 47).

Importante deixar mais uma vez claro que a concepção candidiana dos direitos significou avanços teóricos e pedagógicos e é ela que permite refletirmos em novos direitos incluídos na escola, por isso, apesar de problematizá-la, como estamos fazendo aqui, reconhecemos sua importância histórica e não cobramos que, naquele momento, outra teoria fosse desenvolvida. Há um ímpeto genuinamente democrático em Candido (2011, p. 176), por exemplo, em sua definição de literatura, que considera "da maneira mais ampla possível, todas as criações de toque poético, ficcional ou dramático em todos os níveis de uma sociedade, em todos os tipos de cultura".

Se o trecho terminasse aí, teríamos uma definição democrática nos moldes que defendemos neste artigo, porém, ele continua, "desde o que chamamos de folclore, lenda, chiste, até as formas mais complexas e difíceis da produção escrita das grandes civilizações" (CANDIDO, 2011, p. 176), e estabelece hierarquias entre diferentes manifestações culturais, em que a "das grandes civilizações" é a mais difícil e complexa, sendo o ponto de chegada, enquanto as populares, menos difíceis e menos complexas, são apenas o ponto de partida. Muitos trabalhos de estética poderiam demonstrar, sob critérios ocidentais definidos pela elite (nem sempre intelectual), a maior complexidade dessas obras, mas o que defendemos aqui é: ao se avaliar com critérios específicos e internos das mais diversas culturas, não há hierarquizações possíveis. É claro que existem fabulações estapafúrdias entre as manifestações culturais não canônicas e não clássicas de todas as culturas, 
${ }^{5} \mathrm{E}$ demais membros de projetos de pesquisas liderados por ela, como o projeto "Circulação Transatlântica dos Impressos: a globalização da cultural no século XIX (1789-1914)": http://www. circulacaodosimpressos. iel.unicamp.br/index. php?cd=3\&lang $=$ pt o que não costuma ser claro é que elas também existem em obras canonizadas pelas elites.

Além disso, pesquisadores, como Márcia Abreu (2006) ${ }^{5}$, revelam, ao analisar, por exemplo, a troca de correspondências entre autores e editores de revistas e livros, ou entre autores e membros de academias de letras, que a canonização de um autor pode estar mais vinculada a critérios subjetivos, extraliterários e de interesses pessoais e políticos do que a critérios estéticos e a presença de uma qualidade da literariedade. Assim, além de a recepção de uma obra também ser influenciada por esses critérios, muito do que hoje faz parte do cânone, da alta literatura, era um mero texto mercadológico em seu período de circulação.

Voltando a Candido, para compreendermos melhor a problemática que nos impõe, vejamos o que ele diz na passagem abaixo:

Em nossa sociedade há fruição segundo as classes na medida
em que um homem do povo está praticamente privado da
possibilidade de conhecer e aproveitar a leitura de Machado
de Assis e Mário de Andrade. Para ele, ficam a literatura de
massa, o folclore, a sabedoria espontânea, a canção popular, o
provérbio. Estas modalidades são importantes e nobres, mas
é grave considerá-las como suficientes para a grande maioria
que, devido à pobreza e à ignorância, é impedida de chegar
às obras eruditas. (CANDIDO, p. 188-189)

Essa passagem demonstra que, apesar de haver um esforço por parte do autor em pensar um acesso democrático e igualitário das produções literárias, ele ainda estabelece uma oposição hierárquica entre a cultura "popular" e a "erudita". Ele associa diretamente a pobreza e a ignorância a gêneros como "literatura de massa", "folclore", "sabedoria espontânea", "canção popular" e "provérbio" ao mesmo tempo que estabelece as "obras eruditas" como um ponto a se chegar, colocado como superior. Em síntese, "não há dúvidas que no conflito entre a civilização e o primitivismo, a literatura e o folclore, Antonio Candido escolhe o primeiro polo da disputa" (MELO, 2020, p. 32). Em outro momento, o texto de Candido dá a entender que uma sociedade equitativa só será efetiva quando as classes menos privilegiadas tiverem acesso à cultura erudita. Como nos diz o autor: "para que a literatura chamada erudita deixe de 
ser privilégio de pequenos grupos, é preciso que a organização da sociedade seja feita de maneira a garantir uma distribuição equitativa dos bens" (CANDIDO, 2011, p. 188).

Existe uma ideia latente em Candido de que é preciso se criar pontes para que as classes menos favorecidas tenham acesso às produções literárias e culturais das mais favorecidas. Trata-se de uma ponte unilateral em que só há uma única passagem que leva de um caminho a outro e nunca uma troca em dois ou múltiplos vetores. É preciso analisar essa visão, de modo que não seja lida como simplesmente um ato altruísta/benevolente/missionário das elites e do sistema escolar (que reproduz as ideologias dos grupos dominantes) com os estudantes pertencentes aos grupos subalternizados, uma vez que, como nos lembra bell hooks (2017, p. 53), “[...] nenhuma educação é politicamente neutra". Seria por demais ingênuo não questionarmos essa educação "democrática" em que a maior parte das obras levadas à sala de aula é escrita por autores brancos, heterossexuais, de classe média ou alta e ocupantes de lugares importantes nas esferas de poder no país.

Paulo Freire (2019, p. 180) afirma que essa postura que vê nas classes subalternizadas uma "falta de cultura" nada mais é do eu um dos mitos da ideologia opressora, "o da absolutização da ignorância". Ao reconhecer os outros como ignorantes, o sujeito se reconhece como o que sabe, ou que nasceu para saber. "A sua palavra passa a ser 'verdadeira', que impõe ou procura impor aos demais. E estes são sempre os oprimidos, roubados de sua palavra". Colocando Freire em diálogo com Grada Kilomba (2019, p. 53), ela diz que "as estruturas de validação de conhecimento que definem o que é erudição 'de verdade' e 'válida', são controladas por acadêmicas/os brancas/os", sujeitas/os que declaram suas perspectivas como universais. Trata-se de um discurso inegavelmente excludente que rouba a palavra aos subalternizados. Só é possível mudar essa relação desigual e antidemocrática desvelando-a, denunciando-a e tentando encontrar caminhos para uma sociedade mais justa e, no caso do nosso campo de estudo, para que o ensino de literaturas acolha a todos os saberes e modos de ser, sem hierarquização.

Ainda assim, voltando à potência democrática do texto, há trechos em que Candido argumenta de modo multicultural, exemplificando sua definição de literatura por meio do uso 
de menções aos cantos indígenas. Isso faz com que ele seja ainda mais inclusivo do que parte de sua recepção, que ignora esses trechos e cristaliza, em suas leituras, apenas o viés da hierarquização das culturas. Quando Candido (2011, p. 190) fala em "intercomunicação" entre culturas populares e eruditas, demonstrando que o obstáculo entre eles "pode ser a falta de oportunidade, não a incapacidade" (CANDIDO, 2011, p. 191), parece dar uma guinada para a legitimação igualitária de ambas as culturas, mas ele continua o trecho caracterizando a intercomunicação como contato entre "níveis culturais" e volta para a hierarquização pela escolha lexical de "níveis", em que há os inferiores e os superiores.

Um último exemplo da relevância que o elemento "classe" ganha no texto de Candido (2011, p. 192) se dá ao explicar o "poder universal dos grandes clássicos, que ultrapassam a barreira da estratificação social e de certo modo podem redimir as distâncias impostas pela desigualdade econômica, pois têm a capacidade de interessar a todos e portanto devem ser levados ao maior número". Chama atenção o uso de "universal" para caracterizar os "grandes clássicos", afinal, apesar da vontade ocidentalista da universalidade, não é fato que as obras canônicas do ocidente teriam os mesmos sentidos ou os mesmos valores atribuídos em toda e qualquer cultura.

Por outro lado, no último parágrafo do texto, Candido (2011, p. 193) defende que não deve haver uma separação iníqua entre cultura popular e erudita, criando dois tipos incomunicáveis de interlocutores. Nas palavras do autor:

Portanto, a luta pelos direitos humanos abrange a luta por um estado de coisas em que todos possam ter acesso aos diferentes níveis de cultura. A distinção entre cultura popular e erudita não deve servir para justificar e manter uma separação iníqua, como se do ponto de vista cultural a sociedade fosse dividida em esferas incomunicáveis, dando lugar a dois tipos incomunicáveis de fruidores. Uma sociedade justa pressupõe o respeito dos direitos humanos, e a fruição da arte e da literatura em todas as modalidades e em todos os níveis é um direito inalienável.

No trecho acima evidencia-se um genuíno desejo e busca de se contribuir para pensar um ensino de literaturas mais democrático, no qual literaturas produzidas em diferentes esferas de poder (ele somente destaca a questão da classe) 
possam ser usufruídas tanto pelo "popular" quanto pelo "erudito". Não fosse novamente o uso de "níveis" e todo o argumento ao longo de seu texto, a conclusão de Candido nos contemplaria ainda hoje. Entretanto, assevera Marcos Natali (2006, p. 33), textos como esse evocam debates sobre direitos culturais e acabam por incorrer em um impasse "no momento em que o direito à cultura passa a ser visto não apenas como um acesso a bens culturais privilegiados - à alta cultura -, mas também como direito à especificidade cultural, ou seja, o direito à própria produção cultural".

Como pontua Grada Kilomba (2019), as formas de saber que não se enquadram na ordem euro-norte-cêntrica de conhecimento têm sido continuamente rejeitadas, sendo, por isso, urgente descolonizar a ordem do conhecimento. Destarte, o que buscamos em nossas pesquisas e neste artigo é, em concordância com Melo (2020, p. 38), "explicitar os mecanismos de colonialidade (hierarquização e subalternização de culturas e modos de vida) nessas grandes obras", como a de Candido, para

desnaturalizar os seus pressupostos, questionar os "vínculos placentários" entre o Brasil e o Ocidente, e descortinar outros horizontes possíveis - além das possibilidades apresentadas pelo sistema - para ser, estar no mundo e conceber a vida.

Ao longo da leitura de "O direito à literatura" (2011), percebemos que a defesa à democratização do ensino de literaturas e aos direitos humanos, no texto, está centrada na ideia de classe, isto é, de garantir às classes econômicas e sociais subalternas o acesso aos bens culturais das classes econômicas privilegiadas, mas em via de mão única, sem que os bens culturais populares sejam incluídos e disseminados entre as elites. Essa visão, muito difundida nas décadas de 80 e 90 no Brasil, insere o pensamento candidiano no arco nacionalocidental, que "longe de ser um bloco de doutrinas e ideias homogêneas vindo de um grupo social igualmente homogêneo com finalidade de dominar povos não ocidentais" (MELO, 2020, p. 27), pensa a literatura por meio dos olhos europeus, de um lado, e nacional de outro, buscando defender uma literatura genuinamente brasileira sem romper com os padrões europeus de legitimação cultural e artística. 


\section{A urgência de um olhar interseccional para a educação literária: por uma construção democrática do ensino de literaturas}

Como destacamos anteriormente, Antonio Candido apenas vislumbra as diferenças de classe que, por sua vez, possibilitariam a produção de diferentes vertentes culturais, as quais ele nomeia de "populares" e "eruditas". Porém, as noções de classe não dão conta por si mesmas das desigualdades em nossa sociedade. Diversas autoras contemporâneas, como Lélia Gonzales (2020), bell hooks (2017) e Patrícia Hill Collins (2021), apontam a necessidade de um olhar interseccional quando se faz uma análise dos sujeitos sociais, e destacam que sujeitos subalternizados tendem a ser mais espoliados de seus direitos básicos. Assim, ao lado da classe, categoria que não pode ser excluída do olhar interseccional, as autoras incluem outros elementos como gênero, sexualidade e etnia. Isso nos possibilita alargar o pensamento de Candido e entender que o que ele nomeia por popular abrange uma ampla gama de grupos assujeitados por uma sociedade falocêntrica, branca, heterossexual, machista, tais como os/as negras/os, os/as indígenas, populações do campo, sujeitos LGBTQI+, entre inúmeros outros. E, no que diz respeito a textos literários produzidos por tais sujeitos, ainda hoje é difícil encontrá-los nas escolas brasileiras, sendo usada como justificativa para isso a necessidade de se ensinar (somente) a cultura "erudita". Ou seja, continua-se a defender um trabalho com uma cultura única.

Dentre as nossas teses, destaca-se a de que o pensamento colonial está arraigado ainda hoje em nossas noções de cânone literário. Márcia Abreu (2006, p. 11) apresenta-nos que, na virada do século XX para o XXI, a Folha de São Paulo promoveu a eleição dos melhores romances mundiais e dos melhores brasileiros de todos os tempos. Dentre os mundiais, apenas um, o $5^{\circ}$ deles, é do Brasil, o Grande Sertão: Veredas de Guimarães Rosa, todos os outros nove pertencem ao eixo norte-cêntrico, sendo um estadunidense e os demais europeus.

Já em relação aos melhores romances brasileiros, temse em ordem crescente Grande Sertão: veredas, Dom Casmurro, Memórias Póstumas de Brás Cubas, Macunaima, Triste fim de Policarpo Quaresma, Quincas Borba, Memórias de um sargento de 
milícias, Vidas Secas, São Bernardo e Memórias sentimentais de João Miramar. Essa segunda lista nos impõe outra questão, apesar de haver nela dois autores negros como Machado de Assis e Lima Barreto, muitas vezes suas obras não são levadas para a escola de modo a trabalhá-las enquanto produções de sujeitos negros, há um branqueamento ou mesmo apagamento da questão racial nesses autores. Ron Scapp em uma conversa com bell hooks muito contribui para refletirmos acerca desse tópico, sobretudo quando ele, referindo-se à Toni Morrison, uma escritora negra, diz que a importância e o impacto da obra dessa autora são desvalorizados se não for ensinada de um jeito que vai contra a corrente. Levar autores que pertencem aos grupos sociais vilipendiados historicamente (mulheres, negros/as, LGBTQI+, pobres, populações do campo etc.) para a sala de aula de um jeito não subversivo faz apenas com que o currículo seja atualizado superficialmente (HOOKS, 2017, p. 190).

No caso brasileiro, Machado de Assis e Lima Barreto até constam nos currículos escolares, mas de modo não subversivo, na maior parte das vezes. Os demais autores presentes na lista apresentada por Márcia Abreu são homens brancos, o que nos aponta que não há mulheres nessa lista, sejam brancas, negras ou indígenas, não há autores homens indígenas, também sentimos falta de sujeitos LGBTQI+ e de outros grupos subalternizados. Será que esses grupos (que fazem parte dos subalternizados na América Latina) não produziram ou produzem literatura? Será que eles não existem?

Acerca desse questionamento, acreditamos ser importante revisitar o debate aceso em torno da candidatura à Academia Brasileira de Letras de Conceição Evaristo, uma autora negra e de origem pobre. Conceição Evaristo é hoje uma das mais consagradas escritoras brasileiras, possui um discurso de empoderamento e traz muitas questões acerca do racismo e da diáspora negra em sua escrita, mas na eleição para a ABL recebeu apenas um voto. Há uma simbologia e uma mensagem muito clara nisso: os escritores que fazem parte

${ }^{6}$ Encontramos os termos "re-existência" e "reexistência". O primeiro deles em Walsh (2009) e o segundo em Souza (2011) dos grupos marginalizados ainda precisam de muito mais que seu talento para obterem sucesso. Daí a necessidade de lutar e reexistir ${ }^{6}$, a fim não de destruir o cânone por completo, ou proibir/censurar/boicotar o trabalho com obras clássicas nas escolas, mas de repensá-lo, de ampliá-lo, de reparar as 
exclusões históricas que são fruto do preconceito de raça, classe, sexualidade e gênero na composição desse cânone, na composição da educação (literária) e na composição das estruturas sociais.

A escola, enquanto instituição, que tem um grande poder acerca do cânone e das leituras literárias adentráveis em seus muros, muitas vezes possui um papel cerceador. No início de 2020 isso foi escancarado por um documento elaborado pelo governo de Rondônia, no qual distinguia uma lista de 43 livros considerados inadequados às crianças e adolescentes e que deveriam ser recolhidos nas escolas (OLIVEIRA, 2020). Uma censura descarada que acontece de maneira velada desde sempre e que nos remete ao totalitarismo vivido pelo Brasil entre as décadas de 60 e 80 . Ou seja, a diferença cultural é tida como algo perigoso, indesejável àqueles que são contra uma escola democrática.

Em relação à legislação referente ao ensino escolar no Brasil, apenas a partir da Lei das Diretrizes e Bases da Educação Nacional (LDB-1996), a diferença cultural passa a ser mencionada como legítima, contrapondo-se à postura assimilacionista e tutelar do Estado frente aos grupos subalternizados. Apenas em 2003, institui-se a Lei 10.639 (BRASIL, 2003), que torna obrigatório o ensino de cultura afro-brasileira nas escolas públicas e privadas da educação básica, sendo ampliada em 2008 para contemplar a cultura e história indígenas; em 2002 são estabelecidas as Diretrizes Operacionais para a Educação Básica nas Escolas do Campo; e, somente em 2012, as Diretrizes Curriculares Nacionais para a Educação Escolar Indígena. Questões relacionadas à gênero e diversidade sexual, incluindo os direitos da mulher, são ainda mais recentes e limitam-se ao âmbito dos direitos humanos e da saúde, não sendo, ainda, alvo de políticas educacionais específicas. Além de recentes, essas políticas enfrentam problemas para serem implementadas e diversas pesquisas, como a tese de doutorado de Sá (2019), demonstram as fragilidades da aplicação dessas leis no contexto escolar. $\mathrm{Na}$ verdade, tais questões são alvo de um discurso que se quer fazer lei através um absurdo projeto de silenciamento chamado "Escola sem partido", o qual tem como principal veio ético, ou antiético, uma educação não democrática deliberada, uma vez que os adeptos desse discurso desejam que as escolas não 
tratem de questões referentes a gênero, classe, sexualidade ou raça. Ou seja, questões relacionadas de modo direto aos grupos que são historicamente subalternizados no Brasil.

O mais curioso, senão irônico, é que até mesmo os documentos oficiais se colocam enquanto proposições que advogam pela multiculturalidade, sem, no entanto, implementar estratégias e ações que respeitem e fomentem essa pluralidade de culturas, sujeitos, seres, saberes, sexualidades. O que a nosso ver ocorre é a construção de documentos como resposta às demandas sociais advindas, sobretudo, dos povos subalternizados, mas a falta de esforço para que as propostas saiam do papel e ganhem as ruas é obviamente algo calculado, uma vez que questionam o status quo da sociedade brancohetero-patriarcal brasileira. Ou seja, há um mascaramento das reais intenções dos que estão nas esferas de poder. Um exemplo de exclusão dos povos indígenas está na Base Nacional Comum Curricular (BNCC) de língua portuguesa que, ao explicar o que deve compor o ensino de literatura, declara:

Analisar obras significativas das literaturas brasileiras e de outros países e povos, em especial a portuguesa, a indígena, a africana e a latino-americana, com base em ferramentas da crítica literária ou outros critérios relacionados a diferentes matrizes culturais, considerando o contexto de produção e o modo como dialogam com o presente. (BRASIL, 2018, p. 526, grifos nossos)

Assumindo que "indígena" não é um dos "outros países" e, portanto, é um dos outros "povos", o uso de "outros" para se referir ao que não é interno da sala de aula/cultura/país é bastante significativo quanto ao público que se pensa em atingir com o ensino. Dado que, na Base, a literatura indígena não é brasileira, mas sim de "outros povos", e que a BNCC é nacional, estaria ela se desligando da realidade de que, em muitas salas de aula, há (ou deveria haver) estudantes/ professores/funcionários indígenas? Evocamos aqui Gabriel Albuquerque (2018, p. 14) quando ele destaca que:

A sala de aula já traz em si uma série de distinções entre indivíduos e, para além dessas, temos também o que se põe entre os que estão na sala de aula e aqueles que, estando fora dela, são [ou nem são] representados em textos literários. Negros e índios, entre outros, ocupam esse lugar. 
O próprio documento parece reforçar uma distinção abissal na sala de aula. Se ser indígena, ser de outros povos, não é ser brasileiro, faltou a Base definir o que seria exatamente ser brasileiro. Questionamos se a educação literária e artística monocultural, em via de mão única, eurocentrada, falocentrada, heterocentrada, brancocentrada, características que, em linhas gerais e em conjunto, definem as obras literárias cristalizadas no ensino de literatura, contribui para o projeto Escola sem Partido e outras versões tão retrógradas ainda que menos explícitas desse projeto, ou contribui para a implementação de legislações inclusivas como a Lei 10.639? Convidamos ao questionamento: a que $(\mathrm{m})$ serve o modelo de ensino vigente? A que(m) servem nossos esforços e nossos ímpetos democráticos se os jovens, por não se reconhecerem na escola, deixam de frequentá-la?

Os casos e contextos citados - lista dos melhores romances, eleição para Academia Brasileira de Letras, censura em políticas públicas, legislações escolares etc. - são diversos e não igualamos a censura do governo de Rondônia, por exemplo, ao pensamento de Candido sobre o ensino da cultura clássica ou aos documentos oficiais nacionais sobre educação. Porém, em conjunto, os casos demonstram uma grande dificuldade da teoria crítica, dos professores e dos políticos em romperem com uma hegemonia eurocêntrica e norte-cêntrica das obras literárias que devem constar nas listas e livros escolares. Para nós, faz-se de suma importância investigar algumas raízes possíveis dessa dificuldade, uma vez que é preciso ter consciência de em que ponto podemos mudar, de qual postura ética estamos ou não adotando e se tal postura condiz com um ensino que se pense democrático. Afinal, mesmo com muitos problemas, vivemos (ou queremos viver) uma democracia e acreditamos que, como educadores e pensadores, é nosso dever defendê-la e contribuir para que ela se torne cada vez mais equitativa.

Acrescentamos ao nosso incômodo o alto grau de sucesso que o trabalho sistemático com obras pouco canônicas obtém com os discentes, sobretudo, pertencentes aos grupos subalternizados. Muito se ouve a respeito do fato de os alunos não quererem ler, preferirem a tecnologia ao livro, não se interessarem pelas aulas de literatura. Em nosso trabalho enquanto professores, escutamos muito isso de nossos alunos 
e percebemos que grande parte da desmotivação advém do fato de esses sujeitos não se verem representados nas obras, autores e personagens que estão oficialmente na escola. Por outro lado, de modo não oficial, os alunos são grandes leitores e produtores de trabalhos artísticos e literários inferiorizados ou desprezados pela educação formal. Um exemplo: assistimos, com enorme alegria e esperança, a adoção por parte de muitas escolas públicas de competições literárias de poesia marginal, como os Slams (NEVES, 2017), mas que muitas vezes não estão inseridos no cotidiano da escola em si, apenas incorporados ao extracurricular e extraordinário de eventos pontuais: por que não analisar e produzir Slams em aulas de literatura?

Por isso, julgamos importante destacar os sérios problemas da nossa instituição escolar quando consideramos um ensino democrático. A abertura da instituição escolar às diversas camadas populacionais no Brasil é legalmente estabelecida na Constituição de 1988 (BRASIL, 1988) que, em seu artigo 205, declara: "a educação, direito de todos e dever do Estado e da família, será promovida e incentivada com a colaboração da sociedade, visando ao pleno desenvolvimento da pessoa, seu preparo para o exercício da cidadania e sua qualificação para o trabalho".

Até essa data, havia já regulamentado o direito de todos à escolarização, mas a gratuidade era restrita a grupos que comprovassem insuficiência de recursos, o que mantém, na prática, a exclusão. Ou seja, o ensino era ofertado a uma parcela pequena da população brasileira. Sabe-se que ainda hoje há populações que não possuem acesso a e não estão na escola. Dados da Pesquisa Nacional por Amostra de Domicílios Contínua (PNAD), realizada pelo IBGE em 2018 (IBGE, 2019), demonstram que o Brasil possui 11,3 milhões de analfabetos com 5 anos ou mais, sendo que $6,9 \%$ da população brasileira não possui nenhuma instrução. Como a própria pesquisa destaca, é considerado alfabetizado quem consegue ler e escrever um simples bilhete. Ou seja, muitos brasileiros, milhões deles, ainda não fazem parte do "todos" que consta na constituição. Tais dados são ainda mais alarmantes quando observamos o quadro de "Taxa de analfabetismo por sexo, cor ou raça", segundo grupos de idade. Acima dos 15 anos de idade tem-se, em 2018, $7 \%$ de homens analfabetos, $6,6 \%$ de mulheres, sendo 3,9\% a porcentagem da população branca e $9,1 \%$ pretos ou pardos. 
Acima dos 60 anos essas taxas aumentam gritantemente com $18 \%$ dos homens, $19 \%$ das mulheres, $10 \%$ da população branca e $27,5 \%$ da população tida como preta ou parda.

Podemos especular os motivos pelos quais grande parcela da população do país não se encontra incluída na escola, sobretudo quando se trata daquela que compõe muito mais diversidade do que o IBGE reduz a "pretos e pardos". Dentre tais motivos destacamos alguns de ordem material: falta de recursos econômicos, dificuldades de acesso, falta de saneamento básico, estruturas básicas de sobrevivência etc. Contudo, há também os de ordem imaterial que dizem respeito às políticas segregacionistas que existem e são difundidas pelo Estado que indiretamente criam barreiras para o acesso ao espaço escolar (e muitos outros espaços públicos), sobretudo em relação às populações subalternizadas como negros/as, indígenas, população do campo, sem teto, LGBTQI+, etc. (com destaque para os sujeitos que mais se afastam do branco-classe média ou alta).

No documentário Nunca me sonharam (NUNCA, 2017), sobre os projetos, sonhos, dificuldades e fracassos na vida de jovens estudantes e ex-estudantes de escolas públicas das mais diversas localidades do país, há uma reivindicação comum, entre os entrevistados, para que consigam continuar frequentando a escola: serem ouvidos, construírem coletivamente a escola, produzirem conhecimento, produzirem cultura e terem interlocutores. Caso contrário, um aluno não nomeado declara que "a partir do momento que o sonho [a escola] foi tirado de mim, eu desisti dele também", demonstrando que o encurtamento dos sonhos desses jovens é "pior do que oferecer oportunidades não equitativas", porque é matar o futuro (NUNCA, 2017). Mas por que, na linha narrativa do documentário, esses sonhos são encurtados? Ou, como questiona Bernadete Gatti, "cerca de 38\% dos jovens de 15 a 17 anos não estão no ensino médio e não estão no trabalho. A pergunta é: onde eles estão?" (NUNCA, 2017). Para responder, a professora Luciana Lima hipotetiza: "a gente perde para o tráfico, a gente perde para a gravidez, a gente perde, perde, e a gente não consegue manter os meninos na escola. E a gente nunca para e pergunta: por que você não quer ficar na escola?" (NUNCA, 2017). 
A aluna Suzany Félix, de 18 anos, nos ajuda a entender: “a minha raça influencia, mas também a minha cultura influencia: 'não, porque ela é negra, ela ainda mora em [Duque de] Caxias, ela não estudou em um colégio muito bom. E toda a junção dessas três coisas que eu falei, não vai deixar eu concorrer a um lugar melhor" (NUNCA, 2017). O trecho demonstra que não é apenas pela classe que a aluna é discriminada, já que ela própria consegue observar três elementos. Carmem Ribeiro, exestudante de 31 anos, rememora seu período escolar: "a escola para mim foi um lugar de discriminação. É o lugar onde eu sofri tanto discriminação em virtude, na época, de começar a me descobrir lésbica, dar de cara com o racismo, e isso é muito duro para quem é adolescente, para quem está buscando um lugar no mundo" (NUNCA, 2017), reforçando a precariedade institucional da escola em lidar com a negritude e com a sexualidade recém descoberta no período de sua juventude.

Francisco Ronildo da Silva, de 18 anos, após abandonar os estudos e, segundo o relato de sua mãe, passar os dias e as noites olhando para o nada, trabalhando em subempregos, vivendo em condições precárias, sem sonhar e acreditar no futuro, justifica sua escolha de ter saído da escola: "me achava um pouco incapaz, eu não me sentia bem no meio, não me sentia bem com os conteúdos, não conseguia desenvolver" (NUNCA, 2017). O trecho é significativo sobre como o jovem não consegue se identificar com os "conteúdos", que estão ali dispostos de uma forma que o inferioriza, já que a instituição não exerce a escuta, apenas a imposição dos conteúdos. A solução para isso, Felipe de Lima, de 17 anos, cujo depoimento foi responsável por dar título ao documentário, diz ter encontrado sozinho: "acho que nunca me sonharam sendo um psicólogo, nunca me sonharam sendo um professor, nunca me sonharam sendo um médico. Eles não sonharam, não me ensinaram a sonhar, eu aprendi a sonhar sozinho" (NUNCA, 2017).

No livro Diversidade Sexual na Educação: problematizações sobre a homofobia na escola, Wilian Peres (2009, p. 49) diz:

A escola, que deveria ser um lugar de inclusão e respeito da diversidade, muitas vezes perde a sua função e passa a desempenhar outras. Torna-se escola-polícia, escola-igreja, escola-tribunal, orientadas por tecnologias sofisticadas de poder centradas na disciplina dos corpos e na regulação dos prazeres. 
Dessa forma, o espaço escolar se distancia de uma das principais funções da educação "tornar as pessoas preparadas para o convívio com as diferenças por meio da produção de sentimentos e atitudes de fraternidade, solidariedades e igualdade de direitos, valorizando o coletivo e garantindo o acesso à informação" (PERES, 2009, p. 249). Um dos exemplos que o autor traz em seu artigo "Cenas de exclusões anunciadas: travestis, transexuais, transgêneros e a escola brasileira" ilustra muito bem as dificuldades e barreiras que um sujeito subalternizado pelo Estado sofre ao tentar ser incluído na escola. Trata-se da cena vivida de Lilith, descrita pelo autor como uma travesti negra, pobre, candombleira, portadora do vírus HIV que narra, aos 42 anos, um episódio ocorrido na infância, quando ela cursava a quarta série:

Lilith ainda não era travesti e se portava como menino, mas devido aos seus trejeitos femininos sempre era molestada e agredida pelos outros meninos que a humilhavam constantemente. Um dia, após o sinal de retorno do recreio, Lilith dirigiu-se ao banheiro (deixava para ir por último para evitar molestações) e foi atacada por nove meninos que a obrigaram a fazer sexo oral e anal com todos do grupo. Após a experiência da "curra", ficou algum tempo caída no chão, chorando, até ser encontrada pela servente da escola, que a levou até a diretoria, onde fez a queixa e a denúncia dos meninos que a haviam molestado. Após a denúncia, a diretora chamou os meninos envolvidos e constatou que entre eles estavam o seu filho e um sobrinho que, em prantos, negavam a participação do episódio. Após alguns dias, a diretora da escola convocou Lilith e seus familiares para promulgar a sua expulsão por "atentado violento ao pudor". (PERES, 2009, p. 248-246)

O exemplo de Lilith reflete o de muitos e milhões de outros sujeitos que ao longo dos anos, décadas e séculos foram excluídos da Escola e da própria história, os quais vivem imersos em contextos de opressão e marginalização, estigmatizados e discriminados não apenas pela classe econômica que pertencem, mas também pelos corpos que possuem, pelo gênero, pela sexualidade, pela etnia e pelos diversos outros fatores interseccionais e transversais que compõem suas histórias de vida. Pessoas que foram silenciadas, excluídas, perseguidas, mortas e com certa contribuição do sistema escolar, assumindo, o que Peres (2009) denomina, o 
lugar de escola-polícia, escola-igreja, escola-tribunal, uma postura antidemocrática.

O documentário Se Essa Escola Fosse Minha (SE ESSA ESCOLA, 2017), que investiga as experiências de LGBTQI+'s em escolas públicas e privadas do Brasil, traz alguns testemunhos significativos dessa realidade. Melissa, uma mulher transexual de 28 anos, conta:

Eu comecei a me desinteressar pelos estudos, porque o lugar que eu ia, que eu até então frequentava, era o lugar que eu mais recebia preconceitos, discriminação, né, todos esses fatores que começaram a fazer com que eu realmente começasse a perder o ânimo de ir para a escola. [...] para eles [lidar com pessoas LGBT's] é incômodo, porque vai contra tudo aquilo que eles aprenderam desde o ensino fundamental até o ensino superior. [...] não existe um ser humano que permaneça em um lugar onde ele não é aceito. Ele não se sente bem naquele lugar, ele não consegue ter foco nos estudos, ele não consegue ser integralmente dedicado àquele lugar, porque ele não se sente bem naquele ambiente. (SE ESSA ESCOLA, 2017)

Jef, de 23 anos, complementa: "eu cheguei a ter um professor que trabalhava a questão da homossexualidade como uma doença ou como um desvirtuamento. [...] São raros os momentos que eu olho e sinto nostalgia de vivenciar tudo de novo, é meio que tormento lembrar de algumas coisas" (SE ESSA ESCOLA, 2017). Como a educação, como um todo, mas especialmente a literária, que nos propomos a analisar, pode contribuir para que pessoas como Melissa e Jef não encontrem um ambiente tão ríspido em seu período escolar? Como a escola pode servir para que a existência LGBTQI+ não vá "contra tudo aquilo que eles [LGBTfóbicos e conservadores] aprenderam desde o ensino fundamental até o ensino superior"? A abordagem democrática, pelos direitos humanos, mas preocupada apenas com a classe econômica dos estudantes, é suficiente para os problemas que esses alunos negros e LGBTQI+ enfrentam? Em síntese, como podemos garantir que Melissas e Jefs continuem na escola?

Luan, de 15 anos, arrisca um caminho:

no livro de inglês, por exemplo, uma coisa muito básica que poderia acontecer, que já causaria uma normalização. Muitas vezes tem aquela coisa de 'ah, tem essa conversa de um casal, 
${ }^{7}$ Uma preocupação nossa, importante de evidenciar, é a de evitar um "preconceito generalizado contra as escolas públicas [e, no nosso, caso, privadas] e um desejo de expor suas deficiências sem, contudo, lhes dar o devido retorno ainda sem fazer uma análise dos riscos que os resultados de uma pesquisa podem representar para a imagem da instituição" (PAIVA, 2019, p. 19). vamos ouvir essa conversa no radinho da escola', se fosse um casal homossexual isso já traria uma naturalização para as crianças, e é uma coisa muito básica. (SE ESSA ESCOLA, 2017)

Porém, segundo José Zuchiwschi, “o que vemos hoje na escola como instituição é que ela se faz muito por uma via única, que nós chamamos de monocultural. Isso é muito perverso, de certa forma a criança não aprende a conviver e a olhar o universo com o olhar da multiplicidade" (SE ESSA ESCOLA, 2017). Pensamos que é imprescindível destacar esse lugar ideológico assumido pela escola em nossa sociedade para podermos pensar de forma específica no ensino de literaturas. Ele se afasta disso? Ele contribui com esse sistema? Se a resposta for que ele também faz parte e contribui, devemos pensar em como podemos mudar isso, revolucionar esse ensino que por séculos é excludente, já que, para nós, é extremamente difícil pensar em um país democrático, em pessoas que defendam a democracia se a Escola, enquanto uma das principais instituições desse país, ainda não assume um papel central de luta e manutenção da democracia de modo geral - jamais queremos aqui afirmar que toda escola ou todo professor(a) faz isso, mas chamar atenção para a instituição escolar como um todo. ${ }^{7}$

Luciene Azevedo (2018, p. 186) critica que na educação básica, "principalmente no ensino médio", a literatura é apresentada "como um conjunto enfadonho de nomes de autores, datas, características de períodos literários e pouca ou quase nenhuma experiência de leitura dos próprios textos apresentados a eles como literários". A autora defende a necessidade de "contemplar a diversidade de gênero, as problemáticas étnico-raciais, pluralizar a cultura", como "mediação do passado", com o objetivo de dar ao aluno "a oportunidade de discutir o presente" (AZEVEDO, 2018, p. 188). Ao reduzir a aula de literatura ao livro didático, continua a crítica da autora, o ensino "se reduz à estrita periodização literária e à apresentação de autores e obras clássicas relacionadas a cada um dos períodos" (AZEVEDO, 2018, p. 189).

Ao analisar os livros didáticos aprovados no Programa Nacional do Livro Didático (PNLD) 2018, Albuquerque (2018, p. 216) constata o mesmo que Azevedo (2018) sobre o ensino de literatura, e ainda questiona o cânone escolar ao notar que 
"poucos são os romances que tratam do extermínio" indígena, de modo a denunciá-lo. Além disso, continua o autor, o índio aparece no ensino de literatura apenas "representado" de modo eurocêntrico, nunca como autor de obras literárias (ALBUQUERQUE, 2018, p. 217). Uma das tensões brasileiras contemporâneas quanto à garantia dos direitos humanos diz respeito justamente ao extermínio de povos indígenas. Desse modo, o autor reivindica que,

no contexto de sala de aula, em especial no ensino médio, é que se podem discutir as diferenças culturais com os alunos e confrontar textos, argumentos e opiniões, tratando das alteridades, demonstrando como, na formação da sociedade brasileira, umas se sobrepuseram a outras cuja sobrevivência se deu apenas por meio da resistência. (ALBUQUERQUE, 2018, p. 223)

O discurso racial-eurocêntrico acaba por invisibilizar e desumanizar diversos povos, muitas vezes aproximandoos da natureza a ser explorada e conquistada. Nessa lógica, muitos foram os povos massacrados (simbólica e fisicamente), já os que sobreviveram e resistiram a tantas e tantas práticas de aniquilamento ainda hoje lutam por condições de vida minimamente aceitáveis. No caso do Brasil, por exemplo, dentre as muitas línguas indígenas que existiam, poucas restaram, e isso é reflexo de uma política colonial implantada pelo Marquês de Pombal no século XVIII que obrigava que se falasse somente a Língua Portuguesa nas terras brasileiras. Há, nesse exemplo, uma violência brutal em que línguas e culturas desapareceram e muitos povos foram despojados dos modos próprios que tinham de se relacionar linguisticamente. E bell hooks, enquanto mulher negra, feminista, (sobre)vivente de uma situação afrodiaspórica fala acerca do ato traumático por trás desse apagamento linguístico. Segundo a autora,

Somente como mulher comecei a pensar nesses negros em sua relação com a língua, a pensar em seu trauma quando foram obrigados a assistir à perda de sentido de sua língua por força de uma cultura europeia colonizadora, onde vozes consideradas estrangeiras não podiam se levantar, eram idiomas fora da lei, renegados. (HOOKS, 2017, p. 224-225) 
A passagem de bell hooks é muito potente por nos permitir questionar a nossa própria língua portuguesa do Brasil como sendo universal em todo território. Na verdade, faltam ainda chegar nas escolas e nos materiais dados referentes às línguas indígenas faladas no Brasil. Segundo o Censo Demográfico realizado pelo IBGE (2010), foram registradas 274 línguas indígenas em terras brasileiras e em uma população de 817.963 pessoas, $17,5 \%$ não fala o português. Isso aponta para uma problemática maior, muito bem desenvolvida por Suzana de Castro (2020), a respeito da heterogeneidade imposta pelo sistema colonial/moderno eurocêntrico que, ainda hoje, se faz presente na escola quando os professores e materiais didáticos ensinam que o país foi descoberto em 1500 por Pedro Álvares Cabral. Essa estudiosa denuncia que tal discurso é marca da nossa heteronomia, uma vez que o que atualmente se chama de Brasil "foi construído em cima do apagamento de memórias de povos originários que aqui habitavam, representantes de etnias e nações diversas, distribuídas de acordo territorialização próprias, que nada têm a ver com as fronteiras atuais do país" (CASTRO 2020, p. 51). Todos, apesar de heterogêneos em relação a distintos hábitos, línguas, culturas, foram reduzidos a "índios" - "assim chamados porque os navegadores europeus supostamente chegaram à América por acaso, desviados do caminho para a Índia" (CASTRO, 2020, p. 51).

Essa discussão empreendida até aqui aponta para um elemento muito importante que queremos ressaltar: o projeto colonialista/capitalista eurocêntrico e norte-cêntrico não foi interrompido com o fim da colonização. A nossa sociedade, ainda hoje, possui múltiplas e variadas formas de apagar sujeitos, culturas, sexualidades etc., calcadas nas políticas coloniais. Na América Latina, e no Brasil de modo particular, nos deparamos com sociedades extremamente racistas, machistas, misóginas, LGBTQIfóbicas e/ou preconceituosas em relação às populações do campo. As políticas educacionais que temos acabam por refletir isso. Pensando nisso, propomos que se repense, com urgência, a educação, de um modo geral, e a literária, em particular, a partir de um viés interseccional e dialógico.

Enquanto as estruturas, os dispositivos e os mecanismos de poder institucional que mantêm os padrões de desigualdade não forem desconstruídos, repensados e refeitos, ouvindo, 
${ }^{8}$ Walsh (2009, p. 8) aponta para os problemas da política "multicultural" como uma abordagem funcional que não se interessa por transformar as estruturas sociais racializadas, e tem como objetivo administrar a diversidade diante do que é visto como "perigo de radicalização de imaginários e agenciamentos". Ou seja, a política multicultural ainda seria uma apropriação das culturas subalternizadas pelo neoliberalismo não com fins de realmente incluir, senão de controlar os possíveis sujeitos potencialmente rebeldes. de fato, aqueles que foram sistematicamente omitidos da história, - inclusive com a participação autoral, neste processo, dos sujeitos até aqui invisibilizados -, não acreditamos que poderemos alcançar equidade, tampouco democracia. Ao criticar a política multicultural, Catherine Walsh (2009) defende a concepção de interculturalidade crítica, modelo que questionaria a abordagem funcional vigente, respondendo aos interesses e necessidades das instituições sociais: trata-se da (re)construção a partir das pessoas que sofreram na história com a subalternização. ${ }^{8}$ Seria, pois, a interculturalidade crítica um processo de reexistência, para um outro imaginário, outra maneira de conviver, de viver em sociedade. Os sujeitos que foram subalternizados, que sofrem com racismo, preconceitos de ordem diversa, apagamento de suas culturas e identidades precisam de espaços de resistência para que existam plenamente.

Não pensemos que esse processo seja algo novo, “... uma agenda descolonizadora já está presente nos processos de resistência e reexistência das populações negras, indígenas e populações brasileiras e do sul global ao longo da chamada modernidade/colonialidade" (BERNARDINO-COSTA et al, 2019, p. 19). Destacamos que também encontramos esses processos nos grupos LGBTQIs, nas populações indígenas, nos diversos movimentos feministas, nos coletivos das populações do campo e demais movimentos populares, como o MST (Movimento dos Trabalhadores Rurais Sem Terra) e o MTST (Movimento dos Trabalhadores Sem Teto), entre muitos outros, de modo a que esses sujeitos subalternizados, a partir de uma atitude decolonial, emergem como pensadores, criadores, ativistas "a fim de construir um mundo novo onde outros mundos também sejam possíveis" (BERNARDINO-COSTA et al, 2019, p. 19). Trata-se de ouvir os silenciados historicamente, de enxergar os invisibilizados, de incluir os excluídos, enfim, de pensar uma sociedade/escola/educação democráticas feitas por, com e para todos.

\section{Considerações finais}

Embora concordemos em partes quando pesquisadores da educação literária afirmam que os clássicos precisam estar presentes na escola pelo fato de ser papel da educação 
apresentar para jovens desprivilegiados bens culturais que, em outro lugar, eles não teriam acesso, isso parece homogeneizar esses grupos e incorrer no perigo de, apesar do ímpeto democrático, cercear o que terão acesso. Pensamos isso não para excluir os clássicos, mas para demonstrar, por exemplo, que esse argumento aplicado exclusivamente na defesa dos clássicos, como é feito, assumindo que os jovens têm acesso às obras periféricas/marginais por si próprios, falha nessa pressuposição e esquece o papel e o potencial de mediação da educação escolar. Nesse sentido, ao revistar Antonio Candido, em “O direito à literatura" (2011), publicado em 1988, percebemos que

os grandes pensadores progressistas, lutando contra o atraso e seus correlatos - a escravidão, o coronelismo, o subdesenvolvimento, a miséria, etc. - para libertar o povo brasileiro de sua subalternidade, acabaram também por reproduzir lógicas de colonialidade, já que hierarquizaram culturas, negando a potencialidade transformadora das não ocidentais e optaram por um roteiro emancipatório que tinha a modernidade europeia como desejado ponto de chegada. Tal constatação não deve servir para julgar moralmente esses personagens históricos, nem tampouco macular a admiração merecida da qual muitos são objetos por suas atuações políticas em momentos importantes da história brasileira. (MELO, 2020, p. 37)

Ao contrário do que impor essa mácula, dialogar com um texto de tamanha importância para o campo literário e da educação literária serve para refletirmos: teriam os jovens brasileiros acesso a bens culturais de qualidade (justamente para não deixarmos de lado o papel de mediação e de curadoria da escola) de LGBTQI+, de movimentos de negritude, de movimentos indígenas, e de outros movimentos de resistência? A pressuposição de que sim, ou o esquecimento dessa questão, desconsidera que mesmo sendo um jovem negro, LGBTQI+ e/ou indígena, o estudante pode não conhecer essas obras ou, ele próprio, deslegitimá-las, já que o processo colonial de apagamento e aniquilamento de povos e de culturas é responsável pela violação do direito de acesso a e do direito de legitimação de esses bens culturais. Além disso, ainda que esses jovens consumam essas culturas cotidianamente, o modo pelo qual consomem não passa pela mediação da escola, que 
poderia transformar e transgredir uma simples música em uma arma de resistência ou, em contextos escolares privilegiados, por exemplo, em uma arma de conscientização e empatia. Ao lado dos clássicos, tão cristalizados na cultura escolar, essas obras podem alcançar uma legitimidade que, para um jovem cujos sonhos foram roubados, legitimaria sua existência, suas raízes, sua história e seu futuro.

Concordamos que cabe à escola apresentar bens culturais que, fora dela, os estudantes não teriam acesso. Por isso, concordamos que as obras clássicas e canônicas podem, ou devem, ser lidas, debatidas e analisadas no contexto escolar. Ao lado delas, sem hierarquias ou inferiorizações, defendemos que estejam outras obras produzidas pelos variados sujeitos pertencentes à cultura brasileira (e não só), as quais muitas vezes encontram-se fora do ambiente escolar e são produzidos por grupos subalternizados. Estamos nos referindo às obras africanas das mais diversas nacionalidades, da diáspora africana, das culturas indígenas, das culturas LGBTQI+, das culturas nordestinas, das culturas das periferias brasileiras, das culturas dos campos, das culturas jovens e de quaisquer outras culturas que se encontrem silenciadas e excluídas dos muros da escola. Obras essas sempre selecionadas pelo trabalho de curadoria por parte da escola, mas uma curadoria interseccional, intercultural, crítica e democrática.

Defendemos ainda que, além da oferta de culturas distantes dos educandos, a escola se preocupe com a representatividade, com o acolhimento que torna o ambiente escolar mais tragável e menos ríspido para que os jovens, ao lidarem com os conflitos identitários na juventude - que por si já é carregada de conflitos -, não sofram as exclusões, as violências e os preconceitos, tal como narrado por diversos LGBTQI+ e negros nos documentários mobilizados neste artigo. Propomos, assim, um ensino dialógico e democrático, para os direitos humanos, em que os sentidos sejam negociados, sempre em busca do combate a qualquer forma de discriminação.

Destacamos, por fim, algumas palavras-chave reiteradamente mencionadas ao longo do artigo, que resumem nossa proposta de reflexão: interseccionalidade, contato cultural em via de mão dupla (e em outros vetores possíveis), dialogismo e negociação de sentidos. Em síntese, essas concepções permitem refletir sobre propostas teóricas, práticas 
e metodológicas na educação literária que, se forem construídas a partir do que esses termos reivindicam, contribuiriam para um ensino democrático em direitos humanos não apenas na via da inclusão das classes subalternas no projeto moderno de país, mas também no acolhimento do outro, na legitimação da cultura do outro, na escuta do que o outro tem a ensinar e contribuir.

\section{REFERÊNCIAS}

ABREU, Márcia. Cultura letrada: literatura e leitura. São Paulo: Editora UNESP, 2006.

ABREU, Márcia. "Circulação Transatlântica dos Impressos: a globalização da cultural no século XIX (1789-1914)”. Disponível em: http://www.circulacaodosimpressos.iel.unicamp.br/index. php?cd=3\&lang=pt. Acesso: 28. Fev. 2021.

ALBUQUERQUE, Gabriel. Literatura e escola - as poéticas ameríndias em condição insular. In: SILVA, Simone B. B. da; PEREIRA, Júlio N. (Orgs.). In: Lingua portuguesa e literatura no livro didático: desafios e perspectivas. Campinas: Pontes Editores, 2018.

AZEVEDO, Luciene. "Sonhando com tempestades": a leitura literária e o livro didático. In: SILVA, Simone B. B. da; PEREIRA, Júlio N. (Orgs.). Lingua portuguesa e literatura no livro didático: desafios e perspectivas. Campinas: Pontes Editores, 2018.

BERNARDINO-COSTA, Joaze et al. Introdução. In: BERNARDINO-COSTA, Joaze; MALDONADO-TORRES, Nelson; GROSFOGUEL, Ramon (org.). Decolonialidade $e$ pensamento afrodiaspórico. Belo Horizonte: Autêntica Editora, 2019. p. 9-26.

BRASIL. Constituição (1988). Constituição da República Federativa do Brasil. Brasília, DF: Senado Federal; Centro Gráfico, 1988.

BRASIL. Lei 9.394, de 20 de dezembro de 1996. Lei das Diretrizes e Bases da Educação Nacional. Estabelece as diretrizes e bases da educação nacional. Brasília: Ministério de Educação e Cultura; Congresso Nacional, 1996. 
BRASIL. Diretrizes Operacionais para a Educação Básica nas Escolas do Campo. Brasília, DF: Conselho Nacional de Educação/ Ministério da Educação; 2002.

BRASIL. Lei 10.639, de 9 de janeiro de 2003. Altera a Lei n. 9.394, de 20 de dezembro de 1996, que estabelece as diretrizes e bases da educação nacional, para incluir no currículo oficial da Rede de Ensino a obrigatoriedade da temática "História e Cultura Afro-Brasileira", e dá outras providências. Brasília: Ministério de Educação e Cultura; Congresso Nacional, 2003.

BRASIL. Lei 11.645, de 10 de março de 2008. Altera a Lei n. 9.394, de 20 de dezembro de 1996, modificada pela Lei n. 10.639, de 9 de janeiro de 2003, que estabelece as diretrizes e bases da educação nacional, para incluir no currículo oficial da rede de ensino a obrigatoriedade da temática "História e Cultura Afro-Brasileira e Indígena". Brasília: Ministério de Educação e Cultura; Congresso Nacional, 2008.

BRASIL. Resolução CNE/CEB n. 5, de 22 de junho de 2012. Define Diretrizes Curriculares Nacionais para a Educação Escolar Indígena na Educação Básica. Brasília: Ministério de Educação e Cultura, 2012.

BRASIL. Base Nacional Comum Curricular. Secretaria de Educação Básica. Brasília: Ministério da Educação, 2018.

CANDIDO, Antonio. O direito à Literatura. In: CANDIDO, Antonio. Vários escritos. 5a. ed. Rio de Janeiro: Ouro sobre azul, 2011.

CASTRO, Susana de. "Condescendência: estratégia pátercolonial de poder". In: HOLLANDA, Heloísa Buarque de (org.). Pensamento feminista hoje: perspectivas decoloniais. Rio de Janeiro: Bazar do Tempo, 2020.

COLLINS, Patrícia Hills. Interseccionalidade. Trad. Rane Souza. $1^{a}$ ed. São Paulo: Boitempo, 2021.

FREIRE, Paulo. Pedagogia do oprimido. 71a. ed. Rio de Janeiro/ São Paulo: Paz e Terra, 2019. 
GONZALES, Lélia. Por um feminismo afro latino americano: ensaios, intervenções e diálogos. Organização RIOS, Flávio; LIMA, Márcia. Rio de Janeiro: Zahar, 2020.

HOOKS, bell. Ensinando a transgredir: a educação como prática de liberdade. Trad. Marcelo Brandão Cipolla. São Paulo: Editora WMF Martins Fontes, 2017.

IBGE. Estudos especiais - O Brasil indígena - língua falada. Disponível em: https://indigenas.ibge.gov.br/estudosespeciais-3/o-brasil-indigena/lingua-falada. Acesso em: $16 / 05 / 2021$.

IBGE. PNAD Contínua 2018: educação avança no país, mas desigualdades raciais e por região persistem. Agência IBGE Notícias. 19 jun. 2019. Disponível em: /agencia-sala-deimprensa/2013-agencia-de-noticias/releases/24857-pnadcontinua-2018-educacao-avanca-no-pais-mas-desigualdadesraciais-e-por-regiao-persistem. Acesso em: 16/05/2021.

KILOMBA, Grada. Memórias da plantação: episódios de racismo cotidiano. Tradução Jess Oliveira. Rio de Janeiro: Cobogó, 2019.

MELO, Alfredo Cesar. Crítica da razão nacional-ocidentalista: por uma nova abordagem pós-colonial nos estudos brasileiros. Alea [online]. 2020, vol.22, n.2, p.17-40. https:/doi. org/10.1590/1517-106x/20202221740.

MIGNOLO, Walter. El pensamiento decolonial: desprendimiento e apertura. Un manifiesto. In: CASTRO-GÓMEZ, Santiago; GROSFOGUEL, Ramón. (org.). El giro decolonial: reflexiones para una diversidade epistémica más allá del capitalismo global. Bogotá: Siglo del Hombre Editores; Universidad Central, Instituto de Estudios Sociales Contemporáneos y Pontificia Universidad Javeriana; Instituto Pensar, 2007. p. 25-46.

NATALI, Marcos. Além da Literatura. Revista Literatura e Sociedade, São Paulo, n. 9, pp. 30-43, 2006.

NEVES, C. A. B. Slams - letramentos literários de reexistência ao/no mundo contemporâneo. Linha D'Água, 30(2), 92-112, 2017. Disponível em: https://doi.org/10.11606/issn.2236-4242. v30i2p92-112. Acesso em: 28/02/2021. 
NUNCA me sonharam. Direção de Cacau Rhoden. São Paulo: Maria Farinha Filmes, 2017. Digital (84 min.). Disponível em: https://www.videocamp.com/campaigns/quarentena-believenms-cc/player. Acesso em: 25/01/2021.

OLIVEIRA, Regiane. Censura de livros expõe 'laboratório do conservadorismo' em Rondônia. El País, São Paulo, 07 fev. 2020. Disponível em: https://brasil.elpais.com/brasil/2020-02-08/ censura-de-livros-expoe-laboratorio-do-conservadorismo-emrondonia.html. Acesso em: 16/05/2021.

PERES, Willian Siqueira. Cenas de exclusões anunciadas: travestis, transexuais, trangêneros e a escola brasileira. In: Diversidade Sexual na Educação: problematizações sobre a homofobia na escola. JUNQUEIRA, Rogério Diniz (org). Brasília: Ministério da Educação, UNESCO, 2009, p. 235- 264.

SÁ, Ana Paula dos Santos de. A descolonização da educação literária no Brasil: das leis 10.639/2003 e 11.645/2008 ao PNLD 2015. 2019. 374 p. Tese (doutorado) - UNICAMP, Instituto de Estudos da Linguagem, Campinas, SP. Disponível em: http://www. repositorio.unicamp.br/handle/REPOSIP/334602. Acesso em: 09 mar. 2021.

SANTOS, Boaventura de Sousa. Para além do pensamento abissal: das linhas globais a uma ecologia de saberes. Novos estudos - CEBRAP, São Paulo, n.79, p.71-94, Nov. 2007. https:// doi.org/10.1590/S0101-33002007000300004.

SE ESSA ESCOLA fosse minha. Direção Fellipe Marcelino e Letícia Leotti. Brasília: Universidade de Brasília (UNB). 2017. Digital (40min). Disponível em: https://www.youtube.com/ watch?v=NHJMDuhruz8\&t=89s. Acesso em: 19/02/2021.

SOUZA, Ana Lucia Silva. Letramentos de reexistência: poesia, grafite, música, dança: hip-hop. São Paulo, SP: Parábola, 2011. $171 \mathrm{p}$.

WALSH, Catherine. Interculturalidad crítica y pedagogia de-colonial: apuestas (des)de el in-surgir, re-existir e re-vivir. Revista (entre palabras), Quito, v. 3, p. 1-29, 2009. 


\section{ABSTRACT \\ Literatures teaching and decoloniality: for a democratic literary education}

What is meant by "democracy" and "human rights" when advocating a democratic literary education? And when advocating the democratization of the arts, especially literature? Due to a discomfort with some of the answers to these questions, crystallized in literary criticism and in literatures teaching practices, this article aims to problematize and reflect upon the conceptions of democracy and human rights that underlie literatures teaching in Brazil, in order to propose a sheer shift based on decolonial theories. To this end, we revisit Antonio Candido's 1988 work "O direito à literatura" (2011), which has become a basic reference in criticism, theory, didactics, and teaching ofliteratures to this day, demonstrating how his theory focuses on economic class and on the one-way presentation of nationaluniversal cultural goods to underprivileged students. Thereafter, although we recognize the historical relevance of Candido's theory, we seek to demonstrate, by reading hooks (2017), Walsh (2009), Melo (2020) and other authors, its insufficiency to deal with the contemporary reality of young people in and out of school. Hence, we reflect on the need for a democratic, human rights-based literatures teaching built in dialogue and negotiation not only with subaltern groups belonging to lower economic classes, but also with groups subalternized by ethnicity, race, gender, sexuality, geographical location, etc., that is, a teaching that is also built through listening.

Keywords: Literary education. Human rights. Democracy. Decoloniality. Literatures teaching. 
Rodrigo Corrêa Martins Machado é professor Adjunto do Departamento de Letras da Universidade Federal de Ouro Preto. Doutor em Literatura Comparada pela Universidade Federal Fluminense; mestre em Letras pela Universidade Federal de Viçosa, como também graduado em Letras - Português e Literaturas de Língua Portuguesa - por esta mesma instituição. Os seus interesses se focalizam no ensino de Língua Portuguesa e literatura, poesia de língua portuguesa e literatura portuguesa.

Douglas Vinícius S. Silva é licenciado em Letras (2015), bacharel em Estudos Literários (2017) e mestre em Linguística Aplicada (2020) pela Universidade Estadual de Campinas (UNICAMP). Sua dissertação de mestrado, na área de Linguagem e Educação, investigou a literatura nacional nas práticas formais escolares e informais digitais do YouTube. Atualmente cursa o doutorado e pesquisa literatura e direitos humanos em narrativas e memórias de ex-estudantes do ensino básico. Em suas pesquisas, lida principalmente com teorias e temáticas relacionadas a ensino de literatura, literatura brasileira, identidade nacional, estudos decoloniais, memória e direitos humanos. 